\title{
COMMENTARY
}

\section{Five Essential Steps for Faculty to Mitigate Racial Bias and Microaggressions in the Classroom}

\author{
Tyler Marie Kiles, PharmD, ${ }^{a}$ Marie Chisholm-Burns, PharmD, PhD, MPH, MBA, a,b,c \\ ${ }^{a}$ University of Tennessee Health Science Center (UTHSC), College of Pharmacy, Memphis, Tennessee \\ ${ }^{\mathrm{b}}$ University of Tennessee Health Science Center (UTHSC), College of Pharmacy, Nashville, Tennessee \\ ${ }^{\mathrm{c}}$ University of Tennessee Health Science Center (UTHSC), College of Pharmacy, Knoxville, Tennessee
}

Corresponding Author: Tyler Marie Kiles, University of Tennessee Health Science Center, College of Pharmacy, 881 Madison Ave., Suite 581, Memphis, TN 38163.Tel: 901-448-3354.Email: tkiles@uthsc.edu

Submitted June 30, 2021; accepted November 15, 2021; ePublished December 2021

Educators must recognize the pharmacy curriculum itself is an instrument which can propagate or discourage systemic racism. The role of pharmacy education in disseminating racial bias through didactics deserves further consideration. While microaggressions have begun to be acknowledged in the pharmacy learning environment, specific guidance on mitigating racial microaggressions in the classroom has not been provided. This paper aims to suggest actionable strategies pharmacy educators may use to mitigate or prevent these negative classroom experiences. In the table included five experiences of racial biases and microaggressions in the classroom are combined with suggested action items in a practical guide for pharmacy faculty members. It is our hope that this commentary will challenge faculty in self-assessing their teaching, to prevent propagating racial biases and to create better learning environments for future pharmacists.

Keywords: diversity, inclusion, bias, microaggression

\section{INTRODUCTION}

On May 25, 2020 George Floyd was murdered by a police officer - a seminal incident that shook the nation. The weeks of worldwide protests in the aftermath of his horrific death as well as the murders of Breonna Taylor, Amaud Arbery, and countless others, reflected the resistance to the violent treatment of Black people by law enforcement across the country. In the midst of this racial reckoning, the COVID-19 pandemic also unveiled the stark racial disparities in our health care system through disparities in rates of infections, deaths and immunizations. Many will remember 2020 as the year of the COVID-19 pandemic, or the year we worked from home, but others will also remember this historic time as the year when the nation realized it could no longer turn a blind eye to the ongoing pandemic of systemic racism.

The American Association of Colleges of Pharmacy (AACP) has long supported Equity, Diversity, and Inclusion. ${ }^{1}$ This past year, there was a renewed fervor for discussions on wide-ranging topics in this arena - from diversity, equity and inclusion, to privilege, anti-racism, implicit/unconscious bias and the social determinants of health with many sessions provided by pharmacy professional organizations. Through this programming, there were numerous calls to action for pharmacy educators to become more aware of biases and recognize the existence and effects of systemic racism. However, as educators are familiar, after Knowledge and Understanding in Bloom's Taxonomy come Application, Analysis, Evaluation, and Creating. ${ }^{2}$ In other words, now is the time for action.

Action steps to address systemic racism in pharmacy practice have been suggested, however, the role of pharmacy education in disseminating racial bias through the classroom deserves further consideration. ${ }^{3}$ Educators must recognize the pharmacy curriculum itself is an instrument which can propagate or discourage systemic racism. ${ }^{4}$ For example, studies have shown the medical curriculum has historically oversimplified race and disease presentation in the curriculum, contributing to diagnostic and treatment bias. ${ }^{4,5}$ Studies have also shown despite expressed commitment to caring for the medically underserved upon entering medical school, medical students display increasingly negative attitudes towards the medically underserved during the four years of medical school curriculum. ${ }^{6}$ While research on this topic in pharmacy is scarce, an exploratory study of the experiences of underrepresented racial minority pharmacy students found that they felt the curriculum "perpetuated the social hierarchy" and was a "continuous representation of White people". ${ }^{7}$ This bias in curriculum is likely transmitted unconsciously, without malicious intent. The learning environment is impacted by the didactic curriculum, as well as the "hidden curriculum" - the curriculum of unplanned values, beliefs, and norms, but learned by students all the same (ie, "unwritten rules). ${ }^{8}$ Nevertheless, the manner in which race is portrayed in pharmacy school can have unintended consequences of negative classroom experiences. 
Student experiences of racial microaggressions in health professional programs have also been described..$^{9,10}$ Microaggressions, defined as a subtle, powerful, and often unintentional form of discrimination have implications for wellness and success for students of racial/ethnic minorities. ${ }^{11}$ Types of racial microaggressions are wide-ranging, including: assumptions of lesser intelligence, of criminality or dangerousness, or that one's cultural background and communication styles are pathological; and receiving environmental cues of being unwelcome or devalued. ${ }^{12}$

Microaggressions like these and other understated indignities reveal biases and send messages that cumulatively result in students feeling "othered" and out of place. ${ }^{12}$ While microaggressions have begun to be acknowledged in the pharmacy learning environment, specific guidance on mitigating racial microaggressions in the classroom has not been provided. It is important to recognize that pharmacy education has historically been predominately White. In the U.S.

underrepresented minorities account for $33 \%$ of the population, however only $17 \%$ of all students enrolled in PharmD. programs. ${ }^{13}$ The profession is lacking in diversity - not only in student pharmacists, but also in pharmacy faculty. ${ }^{13}$ This has the potential to further marginalize students beyond society's daily impact. Students historically navigate through these isolating experiences alone or through leaning on one another through systems of social support, but faculty also have an opportunity to work to improve the classroom environment through intentional efforts to reduce the dissemination of bias. ${ }^{7,14}$

This paper aims to suggest actionable strategies pharmacy educators may use to mitigate or prevent the microaggressions triggered by these negative classroom experiences. The perceived biases and microaggressions described in this paper have been exhibited by well-meaning educators and genuinely nice people. These experiences have also been reported in other areas of higher learning. However, it is our specific aim to frame these concepts in an actionable and practical manner.

In the table, (See Table), five experiences of racial biases and microaggressions in the classroom are combined with suggested action items to provide a guide for pharmacy faculty. This guide includes a list of things to Avoid, essentially a "What Not to Do" list, supported by examples; and recommendations to do Instead or "How to Do it Differently". It is our hope that this commentary will challenge faculty in self-assessing their teaching, to prevent propagating racial biases and to create better learning environments for future pharmacists.

\section{DISCUSSION}

This guide is not meant to be accusatory or to suggest that educators who don't currently employ these tactics are inherently racist or bigoted. The issues highlighted above are often not deliberate and may seem innocuous to many. However, the lack of understanding of how these actions may be perceived can have unforeseen consequences. Despite strides in recruitment of minority students, pharmacy has made virtually no progress in the representation of underrepresented minority faculty in the last 20 years. ${ }^{13}$ This is concerning, as the presence of minority faculty is a strong facilitator for student sense of belonging. ${ }^{7}$ Through role modeling, students absorb information about what is valued, acceptable, or possible. By overlooking or not confronting social norms, faculty may inadvertently allow pervasive racial biases to be maintained and reinforced. Critics of these initiatives may continue to dismiss microaggressions as students being "oversensitive", but it is important to emphasize that microaggressions are not about just having hurt feelings. Rather, it is about the negative effect that being repeatedly slighted, invalidated, alienated, and dismissed have at both a micro (biological) and macro (social) level. ${ }^{15}$ According to a nationwide study of medical students, those who reported experiencing microaggressions reported decreased satisfaction with school, and were more likely to consider medical school transfer or withdrawal, less likely to want to stay at their institution for residency, and less likely to recommend their school to friends. ${ }^{11}$ Negative racial experiences within the pharmacy learning environment may also discourage qualified practitioners of minority racial/ethnic backgrounds from seeking careers in pharmacy education, negatively impacting the aspiration to increase faculty diversity.

As an academy and profession committed to increasing diversity, mitigating racial bias and microaggressions in the classroom is of utmost importance. However, the authors recognize that there are many barriers to effectively engaging race in the classroom. As faculty, it can be difficult to apply new knowledge to current teaching philosophy or teaching styles - it is challenging to unlearn the way we were trained or to adjust the materials we have already created. It can seem time-consuming or even overwhelming to be mindful of or intentional about creating an inclusive classroom environment while juggling all of our other scholastic responsibilities. Willen, a medical anthropologist summarizes the essential challenges of teaching about issues of race and ethnicity in the classroom, namely: 1) the didactic nature of clinical training tends to simplify rather than complicate; 2) the universalizing biomedical gaze tends to ignore cultural and social differences relevant to clinical practice; 3) clinicians and clinical trainees' reluctance to make themselves vulnerable by openly sharing with others their own discrimination experiences or invisible privilege; and 4) the challenge of crafting a safe space or holding environment in which different people are willing to engage with the deep unresolved 
emotions tied to cultural and racial issues. ${ }^{16}$ The simple, practical adjustments outlined in this paper may help to change some of the subtle messages conveyed in the pharmacy curricula and learning environment. Additionally, institutional support to create space for critical self-reflection, additional training, and faculty development in the form of case-based workshops facilitated by experts in the field is recommended to develop an understanding of the impact of implicit biases and microaggressions as well as strategies to address them.

Of note, the table is not intended to be a catch-all for inclusive classroom teaching, but rather a baseline starting checkpoint of sorts for faculty interested in making a sincere effort to make their classroom more inclusive for all students. This work also does not detail the racial biases and microaggressions that may occur within team-based learning (such as being ignored or silenced, insulting jokes/comments or fearing being stereotyped when expressing concerns (i.e. angry Black woman)) or experiential settings (for example, when a preceptor sets lower or higher expectations of a student based on their race/ethnicity or expresses a racially charged political opinion) or in the social arena (such as being repeatedly asked to explain one's hairstyle). ${ }^{7}$ Additionally, this list is not exhaustive as there are many more categories of microaggressions that individuals from marginalized backgrounds may face in the classroom. ${ }^{12}$ This commentary scratches the surface of what truly inclusive classrooms look like, as it does not address the spectrum of race/ethnicity, gender, sexual orientation, socioeconomic status and physical abilities (and intersections of all of the above) of all individuals in pharmacy classrooms. Nevertheless, substituting any other marginalized identity (for example, replacing 'race' with 'gender identity') may permit these recommendations to remain somewhat applicable.

\section{CONCLUSION}

The pharmacy academy is committed to increasing the number of pharmacists from underrepresented racial/ethnic backgrounds to address racial disparities in health care - however, in this endeavor it is crucial that the experiences of students are investigated and strategies to create a nurturing educational environment for all students are provided. In addition to the classroom, effective strategies in team-based and experiential learning environments should also be explored. One thing is clear: simply teaching providers about health care inequities has not resulted in actually reaching equity. Previous approaches focused on disparity statistics and cultural competence training are approaches that identify symptoms of racism but do little to challenge the implicit biases that sustain them. Color-blind instruction is not neutral, as it does not address biases, but rather perpetuates them to the norm. Additionally, the upstream factors and barriers that result in disparities in the demographics of who even gets to sit in the classroom, (such as socioeconomic and education disparities, admissions requirements, lack of mentorship, limited exposure to health careers, etc.) must also be addressed to meet the need for a diversified health workforce. However, by being aware of how students may experience the pharmacy classroom and re-imagining the way things have always been done; pharmacy educators may make progress in combating systemic biases in health care and creating welcoming learning environments for an increasingly diverse student body.

\section{ACKNOWLEDGEMENTS}

The authors would like to acknowledge Kenneth Hohmeier, Jennifer Stewart, and Eric Bailey II for the thoughtful review of this manuscript.

Conflict of Interest Disclosure: Marie Chisholm-Burns serves on the board of directors for the Accreditation Council of Pharmacy Education (ACPE). This manuscript does not represent ACPE or the boards' opinions or views.

\section{REFERENCES}

1. Summary of AACP Equity, Diversity, and Inclusion (EDI) Initiatives. American Association of Colleges of Pharmacy website. Accessed October 26, 2021. Available at: https://www.aacp.org/article/equity-diversity-and-inclusion-ediinitiatives

2. Bloom BS, Englehart MD, Furst EJ, Hill WH, Krathwohl DR. Taxonomy of Educational Objectives - The Classification of Educational Goals. Longmans, Green and Co. Ltd;1956.

3. Arya V, Butler L, Leal S, et al. Systemic racism: Pharmacists' role and responsibility. J Am Pharm Assoc (2003). 2020;60(6):e43-e46. doi:10.1016/j.japh.2020.09.003

4. Amutah C, Greenidge K, Mante A, et al. Misrepresenting Race - The Role of Medical Schools in Propagating Physician Bias. N Engl J Med. 2021;384(9):872-878. doi:10.1056/NEJMms2025768 
5. Nieblas-Bedolla E, Christophers B, Nkinsi NT, Schumann PD, Stein E. Changing How Race Is Portrayed in Medical Education: Recommendations From Medical Students. Acad Med. 2020;95(12):1802-1806.

doi:10.1097/ACM.0000000000003496

6. Crandall SJ, Reboussin BA, Michielutte R, Anthony JE, Naughton MJ. Medical students' attitudes toward underserved patients: a longitudinal comparison of problem-based and traditional medical curricula. Adv Health Sci Educ Theory Pract. 2007;12(1):71-86. doi:10.1007/s10459-005-2297-1

7. Bush AA. A Conceptual Framework for Exploring the Experiences of Underrepresented Racial Minorities in Pharmacy School. Am J Pharm Educ. 2020;84(1):7544. doi:10.5688/ajpe7544

8. Hidden Curriculum. The Glossary of Education Reform website. Updated July 13, 2015. Accessed October 26, 2021. https://www.edglossary.org/hidden-curriculum/

9. Ackerman-Barger K, Boatright D, Gonzalez-Colaso R, Orozco R, Latimore D. Seeking Inclusion Excellence: Understanding Racial Microaggressions as Experienced by Underrepresented Medical and Nursing Students. Acad Med. 2020 May;95(5):758-763. doi: 10.1097/ACM.0000000000003077.

10. Wong G, Derthick AO, David EJ, Saw A, Okazaki S. The What, the Why, and the How: A Review of Racial Microaggressions Research in Psychology. Race Soc Probl. 2014;6(2):181-200. doi:10.1007/s12552-013-9107-9

11. Anderson N, Lett E, Asabor EN, et al. The Association of Microaggressions with Depressive Symptoms and Institutional Satisfaction Among a National Cohort of Medical Students [published online ahead of print, 2021 Apr 30]. J Gen Intern Med. 2021;10.1007/s11606-021-06786-6. doi:10.1007/s11606-021-06786-6

12. Williams, M.T., Skinta, M.D., Kanter, J.W. et al. A qualitative study of microaggressions against African Americans on predominantly White campuses. BMC Psychol 8, 111 (2020). doi: 10.1186/s40359-020-00472-8

13. Campbell HE, Hagan AM, Gaither CA. Addressing Ethnic and Racial Diversity in Pharmacy Faculty Pipeline [published online ahead of print, 2021 Jul 22]. Am J Pharm Educ. 2021;8586. doi:10.5688/ajpe8586

14. Avant, N., Davis, R. Navigating and supporting marginalized identities in dominant pharmacy spaces. Innov Pharm. 2018;9(4) :10.24926/iip.v9i4.1033 doi: 10.24926/iip.v9i4.1033

15. Montenegro R. Microaggressions during medical training-Reply. JAMA. 2016;316(10):1114. doi:10.1001/jama.2016.11622

16. Willen SS. Confronting a "big huge gaping wound": emotion and anxiety in a cultural sensitivity course for psychiatry residents. Cult Med Psychiatry. 2013;37(2):253-279. doi:10.1007/s11013-013-9310-6

17. Avant ND, Penm J, Hincapie AL, Huynh VW, Gillespie GL. "Not to exclude you, but...": Characterization of pharmacy student microaggressions and recommendations for academic pharmacy. Curr Pharm Teach Learn. 2020 Oct;12(10):1171-1179. doi: 10.1016/j.cpt1.2020.05.007.

18. McFarling UL. Dermatology faces a reckoning: Lack of darker skin in textbooks and journals harms care for patients of color. STAT. Published July 21, 2020 Accessed October, 26, 2021. Available at:

https://www.statnews.com/2020/07/21/dermatology-faces-reckoning-lack-of-darker-skin-in-textbooks-journalsharms-patients-of-color.

19. Bedell PS, Spaulding AC, So M, Sarrett JC. The names have been changed to protect the . . . humanity: Person-first language in correctional health epidemiology. Am J Epidemiol. 2018;187(6):1140-1142. doi:10.1093/aje/kwy07 


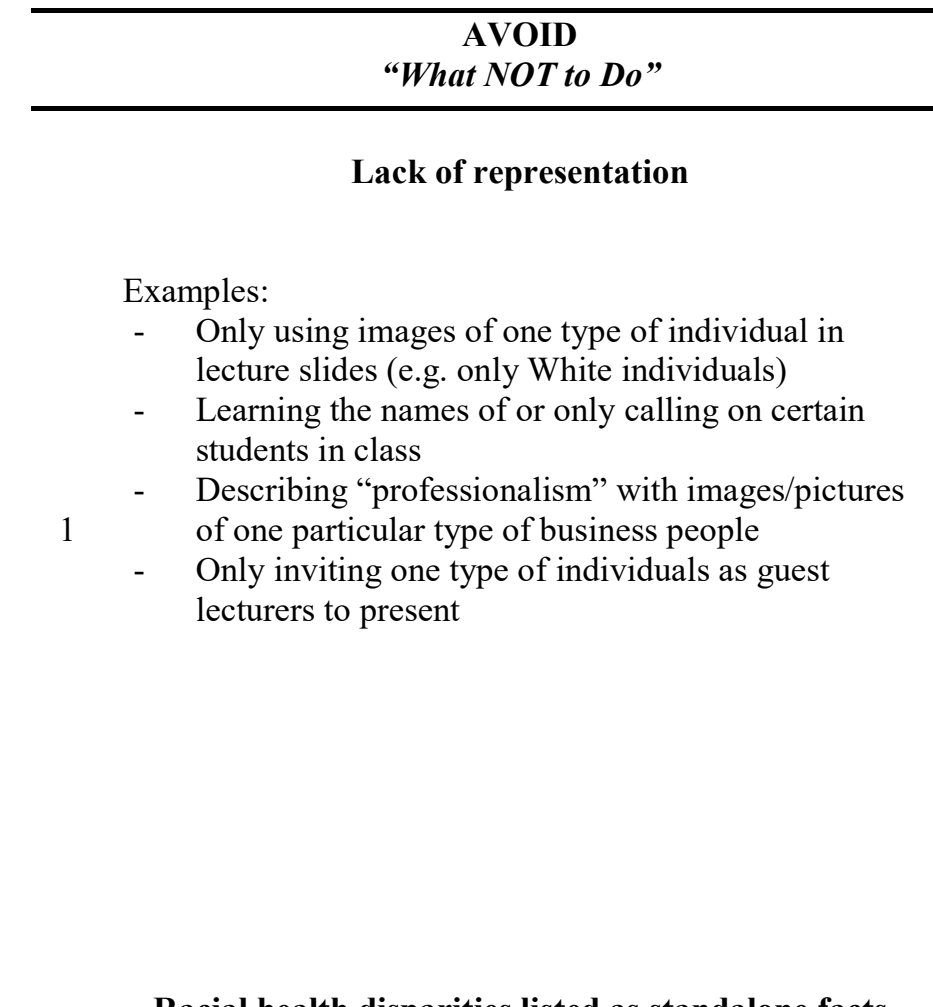

Racial health disparities listed as standalone facts

Examples:

"African Americans are more likely to have diabetes and hyperlipidemia."

2
Implication

INSTEAD

“How to Do it Differently"
This contributes to the normalization of certain groups (i.e. White), and characterizes minority groups as

$$
\text { "other". }{ }^{17}
$$

Additionally, this lack of representation may result in impaired ability to assess conditions in diverse populations (i.e.

dermatologic conditions). ${ }^{18}$

Students who are racial/ethnic minorities may not feel 'seen' in the classroom, and begin to doubt if they belong. 7,9

While these correlations could be true presenting the statistics alone primes learners to attribute differences in

burden of disease due to genetic disposition or innate racial differences. ${ }^{4,5}$

Misusing race as a proxy for genetic difference, socioeconomic status or behavioral risk factors pathologizes race - this contributes to stigma and unequal treatment of patients who are racial/ethnic minorities, and clouds the role of systemic racism in health disparities. $^{4}$

Students may perceive that this strengthens or confirms faculty or other
Purposefully incorporate images, patients, and speakers of color into classrooms and presentations

Recommendations:

- Intentionally search for pictures of patients of other racial/ethnic backgrounds to include in slide deck

- $\quad$ Get to know all students (including your students of color) personally

- Search for images and information to provide to students of other racial/ethnic or religious backgrounds regarding professional hairstyles and clothing

- Invite residents, pharmacists, and faculty from racial/ethnic minority backgrounds to sit on panels and to present on scientific and therapeutic topics in the core curriculum

Note: Take care not to tokenize - i.e. calling on the same BIPOC students, colleagues etc over and over again to serve as the lone representative for their entire group to give the appearance of diversity.

\section{Provide historical and social context for racial health disparities presented}

Recommendation:

"Due to history of segregation, disinvestment from communities of color, Black and Latino Americans are more likely to live in communities with lower socio-economic status and reduced access to education, healthy foods, and healthcare. This reduced access combined with cultural differences in food and perceptions of disease, in addition to the stress caused by living with systemic racism contributes to the racial differences in prevalence of chronic diseases such as diabetes."

Failing to provide this context is a missed opportunity to integrate the social determinants of health into clinical curriculum and to discuss the relationships among race, structural racism and health 


\section{Absent or stereotypical use of race in patient cases}

Examples:

- Only providing a race/ethnicity for patients who are minorities (e.g. Not providing a race/ethnicity for White patients)

Presenting patient cases of stigmatizing conditions (HIV, illicit drug use, obesity, etc) with exclusively patients who are racial/ethnic minorities.

\section{Using "Identity-first" language with regard to} socioeconomic status

Examples:

- Referring to someone as an "under-resourced student"

- $\quad$ Referring to a patient saying “(s)he's an underserved patient" students' existing negative racial biases and stereotypes against minorities.

face is not clinically relevant, then it does not need to be included for any patient case.

Emphasizing and repeating race-disease associations may lead to harms such as delayed diagnosis and medical errors. ${ }^{4}$

Students may perceive that this strengthens or confirms faculty or other students' existing negative racial biases and stereotypes.

Socioeconomic terms are often used interchangeably to describe racial/ethnic minorities, but they are not the same. Blending socioeconomic status and race perpetuates biases by associating skin color with poverty. ${ }^{5}$

"Identity-first" language defines individuals by their differences or impairments - this puts the onus on the person and not the circumstance.

Whereas "person-first" language substitutes for populations of racial/ethnic minorities outcomes. Whereas doing so allows students to fo understanding of factors contributing to health eq

\section{Be intentional and consistent with presenta patient cases}

Do not include race to achieve 'diversity' or incre representation. Be thoughtful about your reason $b$ incorporating race in each case and consider whet cause more harm than good. Recommendation:

- $\quad$ Ensure use of race is intentional and clinical OR

- $\quad$ Provide race/ethnicity for ALL patients (inc patients)

\section{Use Clear and "Person First" lang}

Recommendations:

Be direct - If you mean racial/ethnic minori referring to patients of lower socioeconomic you mean both, say both.

- Consider rephrasing statements as such: "pa under resourced" or "students of lower socio status"
Other examples of shifts in this
Othe

terminology include "persons living with HIV" and "people with diabetes", instead of "HIV patients" and "diabetics". 18

This may be perceived as 'coded' language that suggests that the user 
passing judgement or is using these words as euphemisms for race.

Discomfort or avoidance of discussing race

Examples:

- Whispering or lowering voice volume when mentioning race in describing people or telling stories

5 - Letting student or patient comments that express biases or stereotypes go unchecked

- Claiming to be 'color-blind' or getting defensive when race is brought up
Students can perceive this discomfort which in turn makes them

uncomfortable in the classroom. ${ }^{7}$

This alienates individuals who are racial/ethnic minorities, making them feel invisible, and also inherently validates the ingrained biased perspectives and social norms. ${ }^{14}$
Purposefully discuss race

Recommendations:

- Seek out education or training to learn to dis assertiveness and cultural humility

Don't ignore expressed stereotypes/biases validate the effect that racial microaggressio students who are racial/ethnic minorities.

- Hold yourself, students, or patients accounta or microaggressing comments or misreprese 